\title{
PAPILLARY CARCINOMA IN THYROGLOSSAL CYST: A CASE REPORT
}

Manish Gupta ${ }^{1}$, N. Venkatram Reddy ${ }^{2}$, T. Shankar ${ }^{3}$, S. Muneeruddin Ahmed ${ }^{4}$, Juveria Majeed ${ }^{5}$

\section{HOW TO CITE THIS ARTICLE:}

Manish Gupta, N. Venkatram Reddy, T. Shankar, S. Muneeruddin Ahmed, Juveria Majeed. "Papillary Carcinoma in Thyroglossal Cyst: A case report". Journal of Evolution of Medical and Dental Sciences 2014; Vol. 3, Issue 40, September 01; Page: 10103-10108, DOI: 10.14260/jemds/2014/3310

ABSTRACT: INTRODUCTION: Thyroglossal cyst is a commonly encountered clinical entity resulting due to persistence of Thyroglossal duct and transformation of few embryonic cells into a cyst. It is more common in the supra-hyoid portion of the midline of the neck. The incidence of malignant change in the Thyroglossal cyst is reported as between 1 to 1.8 percent. Papillary carcinoma is common and seen in nearly 80 percent of the cases of the Thyroglossal cysts. Surgical excision with Sistrunk operation is the standard treatment of choice followed by subtotal or total thyroidectomy whenever indicated. CASE PRESENTATION: A female patient aged 31 years presented with swelling in supra-Hyoid region of the neck. FNAC confirmed Thyroglossal cyst; Histopathology showed de novo papillary carcinoma of thyroid. DISCUSSION: windstorm criteria were used to confirm the diagnosis. Post-operative care was taken to exclude primary in the Thyroid gland. CONCLUSIOINS: Primary Malignancy in the Thyroglossal cyst is a rare entity. It is presented here for its presentation as there was no other malignant focus in the Thyroid gland. Thorough work up is necessary to rule out occult primary.

KEYWORDS: Thyroglossal cyst, Thyroglossal duct, papillary carcinoma of the Thyroid, Sistrunk's Operation, Occult primary, primary malignancy of Thyroglossal duct and Tc scan.

INTRODUCTION: Thyroglossal cyst is a benign condition, neo-plastic changes within Thyroglossal cyst is however rare and only a few cases have been reported in medical literature. Recently we encountered a case of Thyroglossal cysts, which turned out to be cases of papillary carcinoma.

CASE HISTORY: A 21 year old female patient presented with complaints of a cystic swelling in upper part of the neck in midline and slightly extending to right since 8 months giving a double chin appearance. The swelling was progressively increasing in size. No other symptoms.

On Clinical examination the mass was $5 \times 2 \mathrm{Cm}$ in dimension. The mass was tender on palpation, firm in consistency, non- pulsatile and not fixed to the underlying structures. Thyroglossal cyst was not the provisional diagnosis, as the Patient had predominantly a midline sub-mental swelling with lateral extension, which is a not a usual presentation for Thyroglossal cyst. There was no evidence of any sinus or fistula. Clinical examination of neck did not otherwise reveal any abnormality.

Examination of the thyroid gland was normal. FNAC of the swelling was done thrice at different places and the opinion given was a) Lymphangioma, (b) Thyroglossal cyst (c) Ranula. Radiological investigation showed no involvement of Hyoid, Laryngeal frame work, trachea and the mandible. USG examination of the Thyroid and the cystic swelling was done. The Thyroid gland was normal. USG guided FNAC was done and it showed features of Thyroglossal cyst.

Thyroid function tests were within normal limits. Hematological and biochemical investigations were found to be normal. 
Sistrunk's operation was done and the mass was excised in Toto. The cyst was extending laterally on the right side with extensive adhesions with surrounding structures. The specimen was sent for Histo-pathological examination. The Post-op period was uneventful. Histopathology report was given as papillary carcinoma of thyroid in a pre-existing Thyroglossal duct cyst or a possibility of a deposit of cystic papillary carcinoma with occult primary in the Thyroid gland. Immunohistochemistry was done. Tumor cells were strongly positive for thyroglobulin, TTF -1, CK- 19.

These features were suggestive of differentiated papillary carcinoma of thyroid. Based on the Histopathological diagnosis the patient was evaluated for a malignant focus in the thyroid which proved to be negative. USG thyroid and Tech scan revealed no abnormality. PET CT of head and neck was done and it revealed normal physiological uptake in nasopharnyx, oropharnyx, Hypopharyx and larynx. There was normal metabolic activity in parotid, thyroid and sub-Mandibular glands.

As clinical, radiological and Tc scan did not reveal involvement of the Thyroid gland no further surgical treatment was undertaken. As the patient was young and had no evidence of lymph node involvement she was advised regular follow up. Patient had been kept under close observation and there has been no evidence of recurrence till date.

DISCUSSION: Benign Thyroglossal duct cysts usually present as asymptomatic, soft, firm, or hard masses in the midline of the anterior neck, and are non-tender and generally movable. Malignant Thyroglossal duct cysts present in the same manner. Carcinoma should be suspected in any Thyroglossal duct cyst that is hard, fixed and irregular or which has undergone recent change.

A history of irradiation of the head and neck or mediastinum during childhood or adolescence should also arouse suspicion of carcinoma.[1]Two cells of origin are described for the malignant tumors developing from the Thyroglossal duct: Thyrogenic carcinoma arising from thyro-embryonic remnants in the duct or a cyst, and squamous cell carcinoma arising from metaplastic columnar cells that line the duct.[1] More than 200 cases of Thyroglossal duct carcinomas have been reported in which papillary carcinoma accounts for $80 \%$ of cases, with the rest being squamous cell carcinoma.[23]

Only one case with both concomitant Histological findings has been reported. [4] All forms of primary thyroid carcinoma can arise in the Thyroglossal duct Except Medullary carcinoma, which arises from parafollicular cells embryologically unrelated to the thyroid.(1) After the Thyroglossal duct cyst has been excised using Sistrunk's procedure and the definitive Histo-pathological report shows malignancy, the thyroid gland must be investigated with radiological and scintigraphic examinations.

Accordingly the extension of surgery must be planned according to the criteria established for differentiated thyroid cancer. [5] In the present case report USG thyroid and Tech scan revealed no abnormality. PET CT of head and neck was done- revealed normal physiological uptake noted in nasopharnyx, oropharnyx, hypo-Pharynx and Larynx. Normal metabolic activity in parotid, thyroid and sub-Mandibular glands was reported.

Usually the Thyroglossal duct cyst is removed by Sistrunk's procedure, wherein excision of the Thyroglossal duct cyst, the central portion of the body of the hyoid bone, and a core of tissue around the Thyroglossal tract to open into the oral cavity at the foramen cecum.[6] In case of malignancy, additional steps should consist of thyroidectomy, radioactive iodine and thyroid suppression, as is the case for differentiated thyroid cancers. 
The thyroid gland is one of the earliest endocrine glands to develop in the human embryo. It descends from the foramen cecum at the base of the tongue to the front of the neck in close relation to the hyoid bone via the Thyroglossal duct. Thyroglossal duct remnants, most commonly a cyst, develops due to incomplete atrophy of the duct which usually occurs by the 7 th fetal week of gestation. Thyroglossal cysts constitute more than $75 \%$ of childhood midline neck masses. It is rare in the adult population (7\%).

It clinically presents as a soft/firm/hard/fluctuant mass that is generally movable in the midline of the neck. Thyroglossal cysts occur along the Thyroglossal tract; Thyro-hyoidal (61\%), supra-hyoid (24\%), supra-sternal (13\%), and intra-lingual region (2\%). The development of malignancy in Thyroglossal cyst is uncommon and approximately 200 cases are reported in the literature since its first description in 1911. Papillary carcinoma is the most common histological type of (80\%) malignancy that occurs in Thyroglossal cyst.

Infrequently squamous, follicular, mixed papillary/follicular, Hürthle cell and anaplastic carcinoma have been reported. Patel et al's analysis: Patients treated with simple excision (10-yr survival 75\%) had a worse prognosis than those with Sistrunk's procedure (100\%). Recently, prognostic risk group assessments are used to identify patients who would benefit from additional total thyroidectomy.

Plaza et al. identified high risk factors: (a) age $>45$ years, (b) past radiation exposure, (c) presence of tumor in the thyroid gland on radiological evaluation, (d) presence of clinical/radiological nodes, (e) tumor $>1.5 \mathrm{~cm}$ in diameter, (f) cyst-wall invasion, and (g) positive margins on Histopathological examination as indicators for additional total thyroidectomy with radioiodine and suppressive hormone therapy.

Additional factors that guide therapy/risk assessment include; (a) gender, (b) tumor characteristics such as histological grade/type, (c)tumor focality, (d) lympho-vascular invasion. In the present case report the diagnosis of a carcinoma in a Thyroglossal cyst was incidental with no additional clinical or investigative evidence to suspect this preoperatively. (7)

The diagnosis of primary TPC in a TDC is one of exclusion using the Widstrom criteria which include:

1) Carcinoma should be in the wall of the Thyroglossal duct remnant.

2) Carcinoma must be differentiated from a cystic lymph node metastasis by histological demonstration of a squamous or columnar epithelium lining and normal thyroid follicles in the wall of the Thyroglossal duct remnant.

3) There should be no malignancy in the thyroid gland or any other possible primary site. $(8,9)$

This latter criterion is highly debated as $11-45 \%$ of all Thyroglossal duct remnant carcinoma cases have a synchronous thyroid carcinoma. 


\section{Source:}

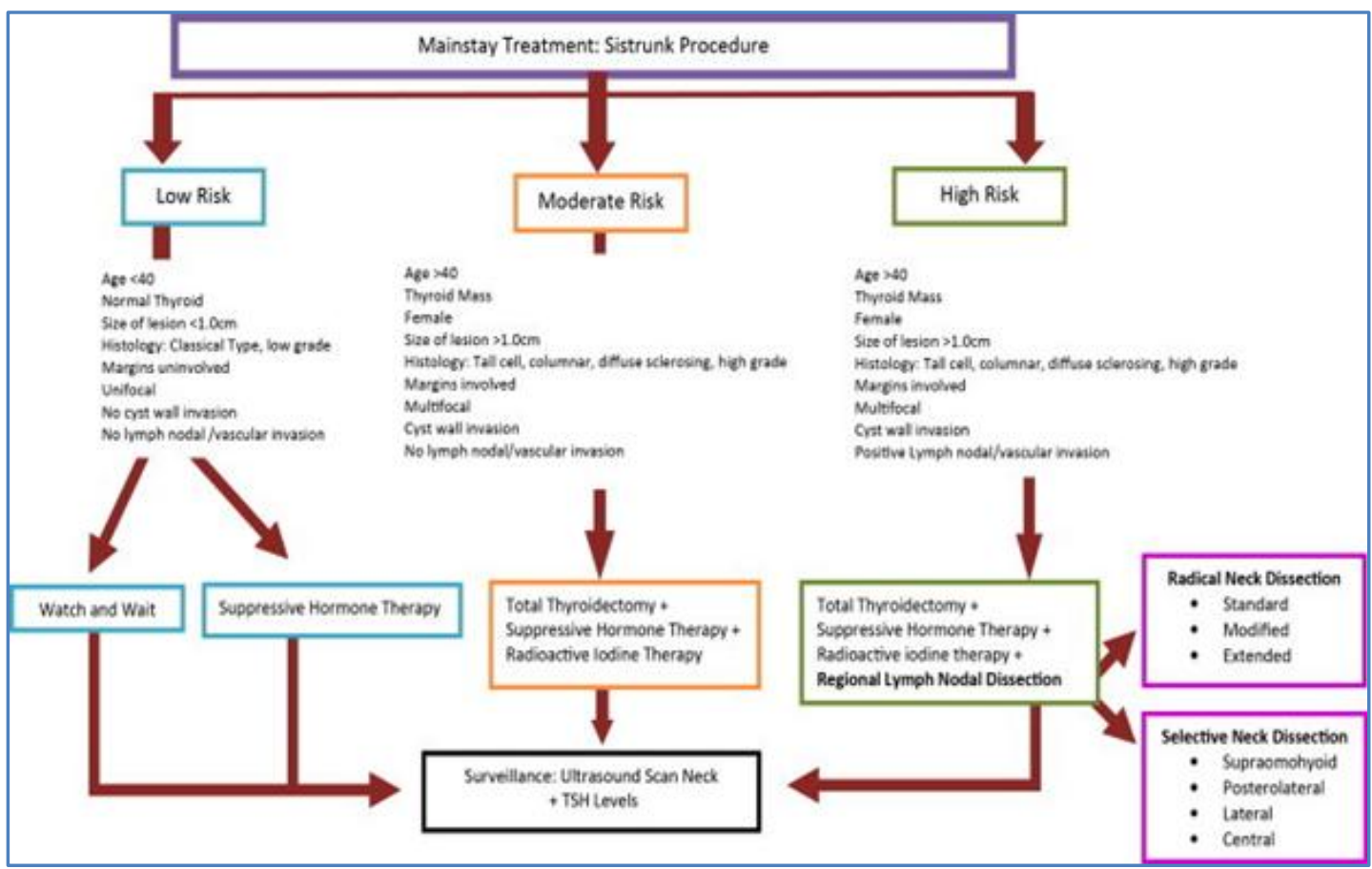

SOURCE: International Journal of surgery of case reports: 2013; 4(1); 58-61. (8), (9) The long-term management of these patients is based on their stratification of low, moderate, and high risk groups. The overall prognosis for PC arising in TgC is excellent, long term clinical follow up with estimation of regular thyroglobulin levels, Scan and Ultrasound is recommended as papillary cancer is known to have a prolonged clinical course ( $>20$ years).

CONCLUSION: Malignant growth occurring de Novo in either the cyst or the duct wall of the Thyroglossal cyst is a rare condition. Windstorm's criteria aptly guide the clinician. Thyroglossal cyst malignancy should be borne in mind especially in case of adults and all the specimens should be examined serially to avoid missing the diagnosis. Owing to rarity of the condition, controversies do exist regarding optimal strategy to be adopted. Management of such cases thus needs to be dealt individually.

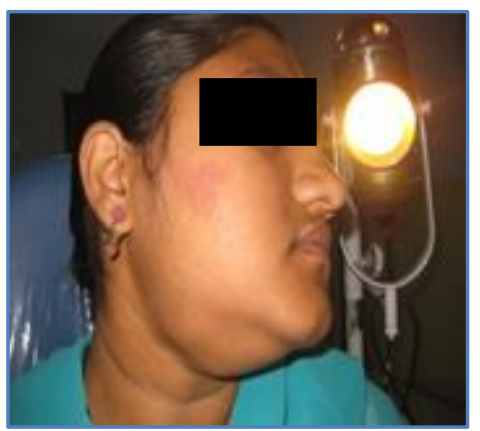

Fig.2: Swelling in the Supra-Hyoid region

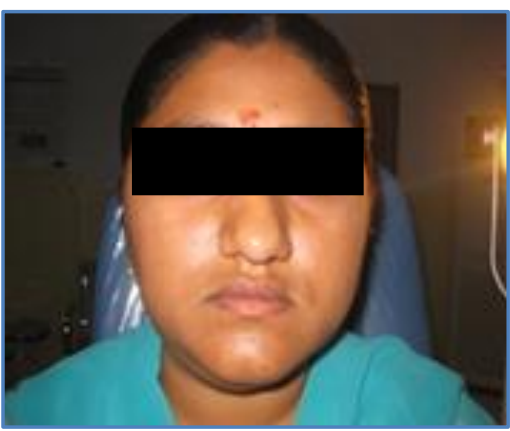

Fig.1: Swelling giving a double chin appearance 


\section{CASE REPORT}

Fig. 3: H \& E histology showing thyroid follicles showing complex branching papillae.

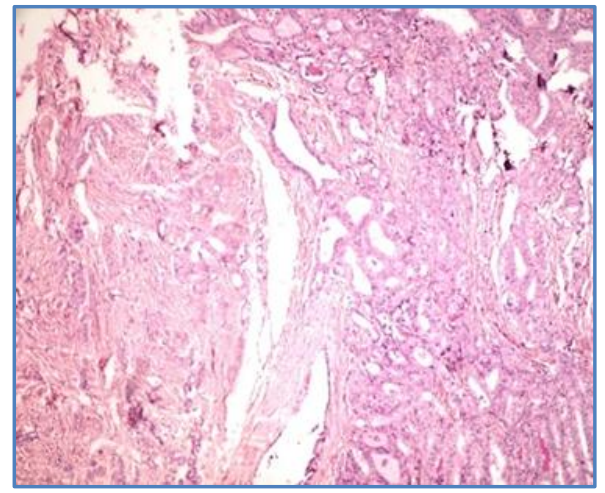

\section{Fig. 3}

Fig. 4: Histology showing nuclear pseudo inclusions and nuclear grooves suggestive of Papillary carcinoma of TGC.

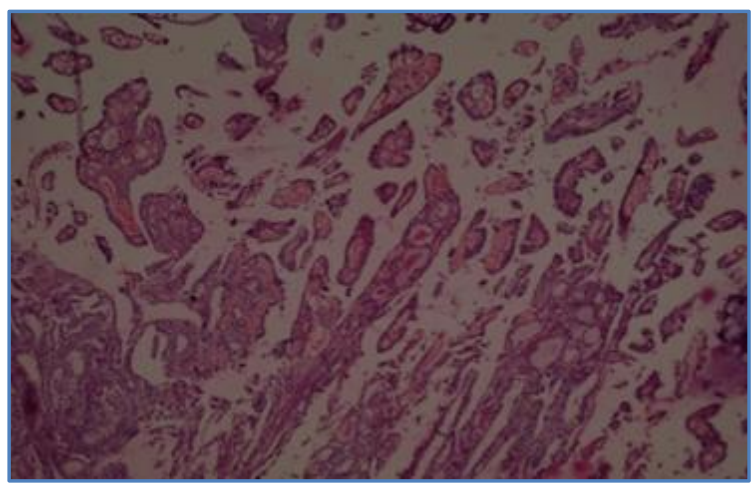

Fig. 4

\section{REFERENCES:}

1. Peretz A, Leiberman E, Kapelushnik J, Hershkovitz E. Thyroglossal duct carcinoma in children: Case presentation and review of the literature. Thyroid. 2004; 14:777-785.

2. Weiss SD, Orlich CC. Primary papillary carcinoma of a thyroglossal duct cyst: Report of a case and literature review. Br J Surg. 1991; 78:87-89.

3. Chu YC, Han JY, Han HS, Kim JM, Min SK, Kim YM. Primary papillary carcinoma arising in a thyroglossal duct cyst. Yonsei Med J. 2002; 43:381-384.

4. Chu YC, Han JY, Han HS, Kim JM, Min SK, Kim YM. Primary papillary carcinoma arising in a thyroglossal duct cyst. Yousei Med j.2002; 43:381-384.

5. Luna Ortiz K, Hurtado-Lopez LM, Valderrama-Landaeta JL, Ruiz-Vega A. Thyroglossal duct cyst with papillary carcinoma: What must be done? Thyroid. 2004; 14:363-366.

6. Mehala Thermabala, Rani Kanthan. Incidental thyroid papillary carcinoma in a thyroglossal duct cyst - management dilemmas. International Journal of Surgery Case Reports; 4 (1):5861. 
7. D Dan, R Rambally, V Naraynsingh, R Maharaj, H Seetharaman. A Case of malignancy in a Thyroglossal duct cyst-recommendations for Management. Journal of the National Medical Association, 104(3-4): 211-214.

8. Hesmati HM, Fatourechi V, van Heerden JA, Hay ID, Goellner JR. Thyroglossal duct carcinoma: Report of 12 cases. Mayo Clin Proc. 1997; 72:315-319.

9. C P R Plaza, M E D Lopez, C E G Carrasco, L M Meseguer, A F Perucho. Management of welldifferentiated Thyroglossal remnant thyroid carcinoma: time to close the debate? Report of five new cases and proposal of definitive algorithm for treatment. Annals of Surgical Oncology, 2006; 13 95): 745-752.

\section{AUTHORS:}

1. Manish Gupta

2. N. Venkatram Reddy

3. T. Shankar

4. S. Muneeruddin Ahmed

5. Juveria Majeed

\section{PARTICULARS OF CONTRIBUTORS:}

1. Assistant Professor, Department of ENT, Osmania Medical College, Hyderabad.

2. Associate Professor, Department of ENT, Osmania Medical College, Hyderabad.

3. Professor and HOD, Department of ENT, Osmania Medical College, Hyderabad.

4. Formerly Professor and HOD, Department of ENT, Osmania Medical College, Hyderabad.
5. Senior Resident, Department of ENT, Osmania Medical College, Hyderabad.

\section{NAME ADDRESS EMAIL ID OF THE CORRESPONDING AUTHOR:}

Dr. S. Muneeruddin Ahmed, 44/118, Prakash Nagar,

Kurnool-518004,

Andhra Pradesh.

Email: ahmedmunirent@gmail.com

Date of Submission: 15/08/2014.

Date of Peer Review: 16/08/2014.

Date of Acceptance: 22/08/2014.

Date of Publishing: 30/08/2014. 